\title{
Ketunggalan Titik Tetap Pada Pemetaan Kontraksi $\theta-\phi$ Di Ruang Metrik Parsial
}

\author{
Malahayati \\ Program Studi Matematika, Fakultas Sains dan Teknologi, UIN Sunan Kalijaga \\ Jl. Marsda Adisucipto No. 1 Yogyakarta, Indonesia \\ Korespondensi; Email: malahayati_01@yahoo.co.id
}

\begin{abstract}
Abstrak
Paper ini mempelajari kontraksi $\theta-\phi$ dan kontraksi tipe Kannan $\theta-\phi$ serta beberapa teorema ketunggalan titik tetap pada ruang metrik parsial. Selanjutnya membandingkan Teorema serupa yang telah dikemukakan oleh peneliti sebelumnya dan membahas contoh sebagai ilustrasi dari teorema yang dibahas.
\end{abstract}

Kata Kunci: titik tetap; kontraksi $\theta-\phi$; kontraksi tipe Kannan $\theta-\phi$; ruang metrik parsial

\begin{abstract}
In this paper, we study the notions of $\theta-\phi$ contraction and $\theta-\phi$ Kannan Type contraction, and some fixed point theorem on partial metric spaces. The results presented in the paper study and consederation some previously results, we also give an example to illustrate our results.
\end{abstract}

Keywords: fixed point; $\theta-\phi$ contraction; $\theta-\phi$ Kannan Type contraction; partial metric spaces

\section{Pendahuluan}

Setelah Matthews [3] memperkenalkan ruang metrik parsial sebagai suatu perumuman dari ruang metrik, banyak peneliti yang mengembangkan konsep ruang metrik parsial dan sifat-sifat topologinya. Konsep ruang metrik parsial mempunyai keunikan dibandingkan ruang metrik yang telah dikenal, hal ini karena pada konsep ruang metrik parsial jarak dari suatu titik ke dirinya sendiri tidak harus nol. Hal inilah yang mendorong para peneliti membawa konsep tersebut dan menerapkannya pada teori titik tetap.

Paper ini akan mempelajari beberapa teorema titik tetap pada pemetaan kontraksi $\theta-\phi$ di ruang metrik parsial yang telah dikenalkan oleh Tao dkk[5], selanjutnya membandingkan teorema tersebut dengan beberapa teorema yang telah di kenalkan sebelumnya oleh Ishak dkk[2]. Teorema-teorema tersebut merupakan pengembangan dari teorema titik tetap yang telah dibahas oleh Matthews [4].

Definisi 1.1[5]: (Ruang metrik parsial). Diberikan himpunan tak kosong $X$. Fungsi $p: X \times X \rightarrow R^{+}$yang memnuhi kondisi berikut $\forall x, y, z \in X$

(P1). $x=y \Leftrightarrow 0 \leq p(x, x)=p(x, y)=p(y, y)$

(P2). $p(x, x) \leq p(x, y)$

(P3). $p(x, x) \leq p(y, x)$

(P4). $p(x, z) \leq p(x, y)+p(y, z)-p(y, y)$

disebut metrik parsial pada $X$, selanjutnya pasangan $(X, p)$ disebut ruang metrik parsial.

Apabila diberikan metrik parsial $p$ pada sembarang himpunan tak kosong $X$, dan fungsi $d_{p}: X \times$ $X \rightarrow[0, \infty)$ yang didefinisikan dengan $d_{p}(x, y)=2 p(x, y)-p(x, y)+p(y, y)$. Maka $d_{p}$ merupakan metrik pada $X$. 
Hal yang serupa dikemukakan oleh Ishak dkk[2], akan tetapi dengan notasi berbeda. Apabila $(X, p)$ adalah ruang metrik parsial, maka fungsi $p^{s}: X \times X \rightarrow \boldsymbol{R}^{+}$yang didefinisikan dengan $p^{s}(x, y)=2 p(x, y)-p(x, x)-p(y, y)$ Adalah metrik pada $X$.

Bola terbuka- $p$ yang berpusat di $x$ dengan jari-jari $\varepsilon>0$ pada ruang metrik parsial $(X, p)$ didefinisikan dengan $B_{p}(x, \varepsilon)=\{y \in X: p(x, y)<\varepsilon\}$. Selanjutnya keluarga semua bola terbuka- $p$ didefinisikan dengan $\left\{B_{p}(x, \varepsilon): x \in X, \varepsilon>0\right\}$.

Setiap ruang metrik parsial $(X, p)$ menghasilkan suatu $T_{0}$ topologi $\tau_{p}$ pada $X$ dengan basisnya adalah keluarga semua bola terbuka- $p$.

Definisi 1.2[5]: Diberikan ruang metrik parsial $(X, p)$

1. Barisan $\left\{x_{n}\right\}$ di $X$ dikatakan konvergen ke $x \in X$ apabila $p(x, x)=\lim _{n \rightarrow \infty} p\left(x, x_{n}\right)$

2. Barisan $\left\{x_{n}\right\}$ di $X$ disebut barisan Cauchy apabila $\lim _{n, m \rightarrow \infty} p\left(x_{m}, x_{n}\right)$ ada (finite).

3. Ruang metrik parsial $(X, p)$ dikatakan lengkap apabila setiap barisan Cauchy $\left\{x_{n}\right\}$ di $X$ konvergen ke $x \in X$ terhdapa topologi $\tau_{p}$, sehingga berlaku $p(x, x)=\lim _{n \rightarrow \infty} p\left(x, x_{n}\right)$

4. Pemetaan $f: X \rightarrow X$ dikatakan kontinu di $x_{0} \in X$ apabila $\forall \varepsilon>0, \exists \delta>0$ sehingga berlaku $f\left(B_{p}\left(x_{0}, \delta\right)\right) \subset B_{p}\left(f\left(x_{0}\right), \varepsilon\right)$

Berikut diberikan beberapa lemma yang menyatakan hubungan antara ruang metrik parsial dan ruang metrik $\left(X, d_{p}\right)$, terkait Barisan Cauchy dan lengkap. Lemma-lemma yang diberikan akan digunakan dalam memebuktikan teorema-teorema pada pembahasan selanjutnya.

Lemma 1.3[5]: Diberikan ruang metrik parsial $(X, p)$

1. Barisan $\left\{x_{n}\right\}$ merupakan barisan Cauchy di ruang metrik parsial $(X, p)$ jika dan hanya jika $\left\{x_{n}\right\}$ barisan Cauchy di ruang metrik $\left(X, d_{p}\right)$.

2. Ruang metrik parsial $(X, p)$ lengkap jika dan hanya jika ruang metrik $\left(X, d_{p}\right)$ lengkap. Lebih lanjut berlaku $\lim _{n \rightarrow \infty} d_{p}\left(x, x_{n}\right)=0 \Leftrightarrow p(x, x)=\lim _{n \rightarrow \infty} p\left(x, x_{n}\right)=\lim _{n, m \rightarrow \infty} p\left(x_{m}, x_{n}\right)$

Lemma 1.4[5]: Jika barisan $\left\{x_{n}\right\}$ konvergen ke $z$ di ruang metrik parsial $(X, p)$ sedemekian hingga $p(x, x)=0$ maka $\lim _{n \rightarrow \infty} p\left(x_{n}, y\right)=p(z, y), \forall y \in X$.

Hal yang serupa dikemukakan oleh Ishak dkk[2], akan tetapi dengan notasi berbeda.

Lemma 1.5[2]: Diberikan ruang metrik parsial $(X, p)$

1. Barisan $\left\{x_{n}\right\}$ merupakan barisan Cauchy di ruang metrik parsial $(X, p)$ jika dan hanya jika $\left\{x_{n}\right\}$ barisan Cauchy di ruang metrik $\left(X, p^{s}\right)$.

2. Ruang metrik parsial $(X, p)$ lengkap jika dan hanya jika ruang metrik $\left(X, p^{s}\right)$ lengkap. Lebih lanjut berlaku $\lim _{n \rightarrow \infty} p^{s}\left(x, x_{n}\right)=0 \Leftrightarrow p(x, x)=\lim _{n \rightarrow \infty} p\left(x, x_{n}\right)=\lim _{n, m \rightarrow \infty} p\left(x_{m}, x_{n}\right)$

Berikut diberikan definisi kontraksi- $\theta$, yang memotivasi definisi kontraksi $\theta-\phi$.

Definisi 1.6[5]: diberikan ruang metrik $(X, d)$. Pemeteean $T: X \rightarrow X$ dikatakan kontraksi- $\theta$ apabila terdapat fungsi $\theta \in \Theta$ dan $k \in(0,1)$ sedemikian hingga $\forall x, y \in X$ berlaku $d\left(T_{x}, T_{y}\right) \neq 0 \Longrightarrow$ $\theta\left(d\left(T_{x}, T_{y}\right)\right) \leq[\theta(d(x, y))]^{k}$ dengan fungsi $\theta:(0, \infty) \rightarrow(1, \infty)$ memenuhi kondisi:

$(\Theta 1)$. Fungsi $\theta$ tidak turun

$(\Theta 2)$. Untuk setiap barisan $\left\{t_{n}\right\} \subset(0, \infty), \lim _{n \rightarrow \infty} \theta\left(t_{n}\right)=1$ jika dan hanya jika $\lim _{n \rightarrow \infty} t_{n}=0$

$(\Theta 3)$. Fungsi $\theta$ kontinu pada $(0, \infty)$ 
$(\Theta 4)$. Terdapat $r \in(0,1)$ dan $l \in(0, \infty]$ sehingga $\lim _{t \rightarrow 0^{+}} \frac{\theta(t)-1}{t^{r}}=l$.

Kondisi $(\Theta 4)$ terlalu kuat, sehingga banyak fungsi yang memenuhi kondisi $(\Theta 1),(\Theta 2),(\Theta 3)$, tetapi tidak memenuhi kondisi $(\Theta 4)$. Oleh karena itu, berikut didefinisikan fungsi yang hanya memenuhi kondisi $(\Theta 1),(\Theta 2),(\Theta 3)$ selanjutnya akan dipelajari lebih dalam sifat-sifat apa saja yang masih berlaku apabila kondisi $(\Theta 4)$ tidak disertakan.

Definisi 1.7[5]: Himpunan yang dinotasikan dengan $\Phi$ adalah himpunan yang memuat fungsi-fungsi $\phi:[1, \infty) \rightarrow[1, \infty)$ dan memenuhi kondisi:

$(\phi 1)$. Fungsi $\phi$ tidak turun

$(\phi 2)$. Untuk setiap $t>1, \lim _{n \rightarrow \infty} \phi^{n}=1$

$(\phi 3)$. Fungsi $\phi$ kontinu pada $[1, \infty)$

Lemma 1.8[5]: Jika $\phi \in \Phi$, maka $\phi(1)=1$ dan $\phi(t)<t$, untuk setiap $t>1$.

\section{Pembahasan}

Berikut diberikan definisi kontraksi $\theta-\phi$ dan kontraksi tipe Kannan di ruang metrik parsial lengkap. Definisi tersebut akan digunakan dalam membuktikan teorema-teorema ketunggalan titik tetap di ruang metrik parsial lengkap.

Definisi 2.1[5]: Diberikan ruang metrik parsial lengkap $(X, p)$ dan pemetaan $T: X \rightarrow X$.

1. Pemetaan $T$ dikatakan kontraksi $\theta-\phi$ apabila terdapat fungsi $\theta \in \Theta$ dan $\phi \in \Phi$ sehingga $\forall x, y \in$ $X$ berlaku

$$
\theta\left(p\left(T_{x}, T_{y}\right)\right) \leq \phi(\theta(p(x, y)))
$$

2. Pemetaan $T$ dikatakan kontraksi tipe Kannan $\theta-\phi$ apabila terdapat fungsi $\theta \in \Theta$ dan $\phi \in \Phi$ sehingga $\forall x, y \in X$ dengan $T_{x} \neq T_{y}$ berlaku

$$
\theta\left(p\left(T_{x}, T_{y}\right)\right) \leq \phi\left[\theta\left(\frac{p\left(x, T_{x}\right)+p\left(y, T_{y}\right)}{2}\right)\right]
$$

Teorema 2.2[5]: Diberikan ruang metrik parsial lengkap $(X, p)$. Jika pemetaan $T: X \rightarrow X$ kontraksi $\theta-$ $\phi$ maka $T$ mempunyai titik tetap tunggal $x^{*} \in X$ sedemikian hingga barisan $\left\{T^{n}(x)\right\}$ konvergen ke $x^{*} \in X$, untuk setiap $x \in X$.

Bukti: Diberikan $x_{0} \in X$ (Fix/tetap). Didefinisikan barisan $\left\{x_{n}\right\}$, dengan $x_{n}=T x_{n-1}$, untuk setiap $n=$ $1,2,3, \cdots$. Substitusikan $x=x_{n-1}, y=x_{n}$ ke pertidaksamaan (1), sehingga diperoleh

$$
\theta\left(p\left(T_{x_{n-1}}, T_{x_{n}}\right)\right)=\theta\left(p\left(x_{n}, x_{n+1}\right)\right) \leq \phi\left(\theta\left(p\left(x_{n-1}, x_{n}\right)\right)\right)
$$

Apabila proses substitusi tersebut diteruskan, maka akan diperoleh pertidaksamaan berikut:

$$
\theta\left(p\left(x_{n}, x_{n+1}\right)\right) \leq \phi\left(\theta\left(p\left(x_{n-1}, x_{n}\right)\right)\right) \leq \phi^{2}\left(\theta\left(p\left(x_{n-2}, x_{n-1}\right)\right)\right) \leq \cdots \leq \phi^{n}\left(\theta\left(p\left(x_{0}, x_{1}\right)\right)\right)
$$

Berdasarkan definisi dari $\theta$ dan aksioma $(\phi 2)$ diperoleh $\lim _{n \rightarrow \infty} \phi^{n}\left(\theta\left(p\left(x_{0}, x_{1}\right)\right)\right)=1$ dan berdasarkan aksioma $(\Theta 2)$ diperoleh

$$
\lim _{n \rightarrow \infty} p\left(x_{n}, x_{n+1}\right)=0
$$

dengan cara yang sama, apabila disubsitusikan $x=x_{m}$ dan $y=x_{m}$, diperoleh 


$$
\lim _{n \rightarrow \infty} p\left(x_{m}, x_{m}\right)=0 .
$$

Selanjutnya, akan dibuktikan bahwa barisan $\left\{x_{n}\right\}$ merupakan barisan Cauchy di ruang metrik $\left(X, d_{p}\right)$. Andaikan barisan $\left\{x_{n}\right\}$ bukan barisan Cauchy di ruang metrik $\left(X, d_{p}\right)$, berarti terdapat beberapa bilangan $\varepsilon>0$ dan subbarisan-subbarisan $\left\{x_{n_{k}}\right\},\left\{x_{m_{k}}\right\}$ di $\left\{x_{n}\right\}$ dengan $n_{k} \geq m_{k} \geq k$ sehingga

$$
d_{p}\left(x_{m_{k}}, x_{n_{k}}\right) \geq \varepsilon
$$

berdasarkan (6), apabila dipilih bilangan yang lebih kecil dari $n_{k}$, missal $n_{k-1}$, berarti diperoleh

$$
\begin{gathered}
d_{p}\left(x_{m_{k}}, x_{n_{k-1}}\right)<\varepsilon . \\
\varepsilon \leq d_{p}\left(x_{m_{k}}, x_{n_{k}}\right) \leq d_{p}\left(x_{m_{k}}, x_{n_{k-1}}\right)+d_{p}\left(x_{n_{k-1}}, x_{n_{k}}\right)<\varepsilon+d_{p}\left(x_{n_{k-1}}, x_{n_{k}}\right)
\end{gathered}
$$

berdasarkan definisi metrik $d_{p}$, diperoleh

$$
d_{p}\left(x_{n_{k-1}}, x_{n_{k}}\right)=2 p\left(x_{n_{k-1}}, x_{n_{k}}\right)-p\left(x_{n_{k-1}}, x_{n_{k-1}}\right)-p\left(x_{n_{k}}, x_{n_{k}}\right)
$$

apabila $k \rightarrow \infty$ dan berdasarkan persamaan (4) dan (5) maka diperoleh

$$
\lim _{k \rightarrow \infty} d_{p}\left(x_{m_{k}}, x_{n_{k}}\right)=2 \lim _{k \rightarrow \infty} p\left(x_{m_{k}}, x_{n_{k}}\right)=\varepsilon
$$

perhatikan pula bahwa

$$
d_{p}\left(x_{n_{k}}, x_{m_{k}}\right) \leq d_{p}\left(x_{n_{k}}, x_{n_{k-1}}\right)+d_{p}\left(x_{n_{k-1}}, x_{m_{k-1}}\right)+d_{p}\left(x_{m_{k-1}}, x_{m_{k}}\right)
$$

dilain pihak

$$
d_{p}\left(x_{n_{k-1}}, x_{m_{k-1}}\right) \leq d_{p}\left(x_{n_{k-1}}, x_{n_{k}}\right)+d_{p}\left(x_{n_{k}}, x_{m_{k}}\right)+d_{p}\left(x_{m_{k}}, x_{m_{k-1}}\right)
$$

apabila $k \rightarrow \infty$ dan berdasarkan (4), (5), dan (7) diperoleh

$$
\lim _{k \rightarrow \infty} d_{p}\left(x_{n_{k-1}}, x_{m_{k-1}}\right)=2 \lim _{k \rightarrow \infty} p\left(x_{n_{k-1}}, x_{m_{k-1}}\right)=\varepsilon
$$

Substitusi $y=x_{n_{k-1}}, \quad x=x_{m_{k-1}}$ ke pertidaksamaan (1), selanjutnya menggunakan (6) dan (8) diperoleh

$$
\theta\left(\frac{\varepsilon}{2}\right) \leq \lim _{k \rightarrow \infty} \theta\left(p\left(x_{m_{k}}, x_{n_{k}}\right)\right) \leq \lim _{k \rightarrow \infty} \phi\left(\theta\left(p\left(x_{m_{k-1}}, x_{n_{k-1}}\right)\right)\right)
$$

Selanjutnya berdasarkan Lemma 1.8, diperoleh $\theta\left(\frac{\varepsilon}{2}\right) \leq \phi\left(\theta\left(\frac{\varepsilon}{2}\right)\right)<\theta\left(\frac{\varepsilon}{2}\right)$

Hal ini kontradiksi. Oleh karena itu, pengandaian salah dan harus diingkar. Jadi yang benar adalah barisan $\left\{x_{n}\right\}$ merupakan barisan Cauchy di ruang metrik $\left(X, d_{p}\right)$.

Selanjutnya, karena $\left(X, d_{p}\right)$ adalah ruang metrik lengkap, dan $\left\{x_{n}\right\}$ merupakan barisan Cauchy di ruang metrik $\left(X, d_{p}\right)$ maka barisan $\left\{x_{n}\right\}$ konvergen. Oleh karena itu, terdapat $x^{*} \in X$ sedemikian hingga $\lim _{n \rightarrow \infty} d_{p}\left(x_{n}, x^{*}\right)=0$. Hal ini sama saja mengatakan

$$
p\left(x^{*}, x^{*}\right)=\lim _{n \rightarrow \infty} p\left(x_{n}, x^{*}\right)=\lim _{n, m \rightarrow \infty} p\left(x_{n}, x_{m}\right)=\frac{1}{2} \lim _{n, m \rightarrow \infty} d_{p}\left(x_{n}, x_{m}\right)=0
$$

Selanjutnya, berdasarkan aksioma (P2), akan ditunjukkan bahwa $x^{*}$ adalah titik tetap pada $T$, yaitu harus ditunjukkan $p\left(T x^{*}, x^{*}\right)=p\left(x^{*}, x^{*}\right)=p\left(T x^{*}, T x^{*}\right)=0$.

Berawal dari atas telah didapatkan bahwa $p\left(x^{*}, x^{*}\right)=0$, dengan menggunakan pernyataan (1) diperoleh $\theta\left(p\left(T x^{*}, T x^{*}\right)\right) \leq \phi\left(\theta\left(p\left(x^{*}, x^{*}\right)\right)\right)$. Berdasarkan definisi $\theta$ dan Lemma 1.8, diperoleh $p\left(T x^{*}, T x^{*}\right)=0$ 
Juga dengan menggunakan pernyataan (1) apabila disubstitusikan $x=x_{n-1}$ dan $y=x^{*}$ diperoleh

$$
\theta\left(p\left(x_{n}, T x^{*}\right)\right) \leq \phi\left(\theta\left(p\left(x_{n-1}, x^{*}\right)\right)\right)
$$

Apabila $n \rightarrow \infty$ dan berdasarkan Lemma 1.4, serta sifat kekontinuan fungsi $\theta$ dan $\phi$ maka diperoleh $p\left(x^{*}, T x^{*}\right)=0$. Jadi, benar bahwa $x^{*}$ adalah titik tetap pada $T$. Selanjutnya akan dibuktikan ketunggalannya.

Andaikan ada $y^{*}$ titik tetap lainnya pada $T$, sehingga $T x^{*}=x^{*} \neq T y^{*}=y^{*}$, dengan demikian didapatkan

$$
\theta\left(p\left(x^{*}, y^{*}\right)\right)=\theta\left(p\left(T x^{*}, T y^{*}\right)\right) \leq \phi\left(\theta\left(p\left(x^{*}, y^{*}\right)\right)\right)<\theta\left(p\left(x^{*}, y^{*}\right)\right)
$$

Hal ini kontradiksi. Jadi pengandaian salah, yang benar adalah titik tetap pada $T$ tunggal.

Teorema 2.2 diatas sejalan dengan yang dikemukakan oleh Ishak dkk[2], perbedaannya adalah bahwa pada Ishak dkk[2] tidak mendefinisikan pemetaan kontraksi $\theta-\phi$. Akan tetapi syarat perlunya diberikan dengan suatu hubungan pertidaksamaan pada metriknya. Untuk lebih jelas, dibahas dalam teorema berikut ini.

Teorema 2.3[2]: Diberikan ruang metrik parsial lengkap $(X, p)$ dan fungsi kontinu $\phi:[0, \infty) \rightarrow[0, \infty)$ yang tidak turun dengan $\phi(t)<t, \forall t>0$. Jika pemetaan $F: X \rightarrow X$ memenuhi kondisi

$$
p(F x, F y) \leq \phi\left[\max \left\{p(x, y), p(x, F x), p(y, F y), \frac{1}{2}(p(x, F y)+p(y, F x))\right\}\right]
$$

untuk semua $x, y \in X$, maka $F$ mempunya titik tetap tunggal.

Bukti: Berdasarkan definisi fungsi $\phi$, jelas bahwa $\lim _{n \rightarrow \infty} \phi^{n}(t)=0, \forall t>0$.

Diberikan $x_{0} \in X$ (Fix/tetap). Didefinisikan barisan $\left\{x_{n}\right\}$, dengan $x_{n}=F x_{n-1}$, untuk setiap $n=$ $1,2,3, \cdots$. Apabila $x_{n_{0}}=x_{n_{0}+1}$, untuk beberapa $n_{0}=0,1,2, \cdots$ maka jelas $x_{n_{0}}$ adalah titik tetap untuk $F$. Apabila $x_{n} \neq x_{n+1}$ untuk setiap $n$, dan berlaku pertidasamaan berikut,

$$
p\left(x_{n}, F x_{n-1}\right)+p\left(x_{n-1}, F x_{n}\right)=p\left(x_{n}, x_{n}\right)+p\left(x_{n-1}, x_{n+1}\right) \leq p\left(x_{n-1}, x_{n}\right)+p\left(x_{n}, x_{n+1}\right)
$$

karena fungsi $\phi$ tidak turun, berdasarkan ketaksamaan (8) maka diperoleh

$$
\begin{aligned}
& p\left(x_{n+1}, x_{n}\right)=p\left(F x_{n}, F x_{n-1}\right) \\
& \leq \phi\left[\max \left\{p\left(x_{n}, x_{n-1}\right), p\left(x_{n}, F x_{n}\right), p\left(x_{n-1}, F x_{n-1}\right), \frac{1}{2}\left(p\left(x_{n}, F x_{n-1}\right)+p\left(x_{n-1}, F x_{n}\right)\right)\right\}\right] \\
& \leq \phi\left[\max \left\{p\left(x_{n}, x_{n-1}\right), p\left(x_{n}, x_{n+1}\right), \frac{1}{2}\left(p\left(x_{n-1}, x_{n}\right)+p\left(x_{n}, x_{n+1}\right)\right)\right\}\right] \\
& =\phi\left[\max \left\{p\left(x_{n}, x_{n-1}\right), p\left(x_{n}, x_{n+1}\right)\right\}\right]
\end{aligned}
$$

Selanjutnya, perhatikan bahwa, andaikan $\max \left\{p\left(x_{n}, x_{n-1}\right), p\left(x_{n}, x_{n+1}\right)\right\}=p\left(x_{n}, x_{n+1}\right)$, maka dari (9) diperoleh $p\left(x_{n+1}, x_{n}\right) \leq \phi\left(p\left(x_{n}, x_{n+1}\right)\right)<p\left(x_{n+1}, x_{n}\right)$.

Hal ini kontradiksi, karena $p\left(x_{n}, x_{n+1}\right)>0$. Sehingga pengandaian salah dan harus diingkar, yang benar adalah $\max \left\{p\left(x_{n}, x_{n-1}\right), p\left(x_{n}, x_{n+1}\right)\right\}=p\left(x_{n}, x_{n-1}\right)$ untuk semua $n$.

Oleh karena itu, pernyatan (9) adalah $p\left(x_{n+1}, x_{n}\right) \leq \phi\left(p\left(x_{n}, x_{n-1}\right)\right)$. Apabila proses ini diteruskan, maka diperoleh

$$
p\left(x_{n+1}, x_{n}\right) \leq \phi^{n}\left(p\left(x_{1}, x_{0}\right)\right)
$$

Sebaliknya, karena $\max \left\{p\left(x_{n}, x_{n}\right), p\left(x_{n+1}, x_{n+1}\right)\right\} \leq p\left(x_{n}, x_{n+1}\right)$, maka berdasarkan (10) diperoleh

$$
\max \left\{p\left(x_{n}, x_{n}\right), p\left(x_{n+1}, x_{n+1}\right)\right\} \leq \phi^{n}\left(p\left(x_{1}, x_{0}\right)\right)
$$


Selanjutnya, perhatikan dahulu bahwa:

$$
\begin{aligned}
& p^{s}\left(x_{n}, x_{n+1}\right)=2 p\left(x_{n}, x_{n+1}\right)-p\left(x_{n}, x_{n}\right)-p\left(x_{n+1}, x_{n+1}\right) \\
\leq & 2 p\left(x_{n}, x_{n+1}\right)+p\left(x_{n}, x_{n}\right)+p\left(x_{n+1}, x_{n+1}\right) \leq 4 \phi^{n}\left(p\left(x_{1}, x_{0}\right)\right)
\end{aligned}
$$

Hal ini menunjukkan bahwa $\lim _{s \rightarrow \infty} p^{s}\left(x_{n}, x_{n+1}\right)=0$.

Selanjutnya, $p^{s}\left(x_{n+k}, x_{n}\right) \leq p^{s}\left(x_{n+k}, x_{n+k-1}\right)+\cdots+p^{s}\left(x_{n+1}, x_{n}\right)$

$$
\leq 4 \phi^{n+k-1} p^{s}\left(x_{1}, x_{0}\right)+\cdots+4 \phi^{n} p^{s}\left(x_{1}, x_{0}\right)
$$

Apabila $n \rightarrow \infty$ hal ini menunjukkan bahwa barisan $\left\{x_{n}\right\}$ merupakan barisan Cauchy di ruang metrik $\left(X, p^{s}\right)$. Karena $(X, p)$ lengkap, maka berdasarkan Lemma 1.5 ruang metrik $\left(X, p^{s}\right)$ juga lengkap, akibatnya barisan $\left\{x_{n}\right\}$ konvergen dalam $\left(X, p^{s}\right)$ misalkan ke $x$, sehingga $\lim _{n \rightarrow \infty} p^{s}\left(x_{n}, x\right)=0$.

Selain itu, diperoleh pula $p(x, x)=\lim _{n \rightarrow \infty} p\left(x_{n}, x\right)=\lim _{n, m \rightarrow \infty} p\left(x_{n}, x_{m}\right)$. Karena $\left\{x_{n}\right\}$ merupakan barisan Cauchy di ruang metrik $\left(X, p^{S}\right)$ ini berarti $\lim _{n, m \rightarrow \infty} p^{S}\left(x_{n}, x_{m}\right)=0$ selanjutnya berdasarkan (11) $\lim _{n \rightarrow \infty} p\left(x_{n}, x_{n}\right)=0$. Berdasarkan definisi $p^{s}$, diperoleh $\lim _{n, m \rightarrow \infty} p^{s}\left(x_{n}, x_{m}\right)=0$. Sehingga

$$
p(x, x)=\lim _{n \rightarrow \infty} p\left(x_{n}, x\right)=\lim _{n, m \rightarrow \infty} p\left(x_{n}, x_{m}\right)=0 .
$$

Selanjutnya ditunjukkan bahwa $p(x, F x)=0$. Andaikan sebaliknya, yaitu $p(x, F x) \neq 0$. Berdasarkan (8), diperoleh

$$
\begin{aligned}
p(x, F x) \leq & p\left(x, F x_{n}\right)+p\left(F x_{n}, F x\right)-p\left(F x_{n}, F x_{n}\right) \leq p\left(x_{n}, x_{n+1}\right)+p\left(F x_{n}, F x\right) \\
\leq & p\left(x_{n}, x_{n+1}\right)+\phi\left(\max \left\{p\left(x, x_{n}\right), p(x, F x), p\left(x_{n}, x_{n+1}\right), \frac{1}{2}\left(p\left(x, x_{n+1}\right),+p\left(x_{n}, F x\right)\right)\right\}\right) \\
\leq & p\left(x_{n}, x_{n+1}\right)+\phi\left(\operatorname { m a x } \left\{p\left(x, x_{n}\right), p(x, F x), p\left(x_{n}, x_{n+1}\right), \frac{1}{2}\left(p\left(x, x_{n+1}\right),+p\left(x_{n}, x\right)+\right.\right.\right. \\
& p(x, F x)-p(x, x))\}) \\
= & p\left(x_{n}, x_{n+1}\right)+\phi\left(\operatorname { m a x } \left\{p\left(x, x_{n}\right), p(x, F x), p\left(x_{n}, x_{n+1}\right), \frac{1}{2}\left(p\left(x, x_{n+1}\right),+p\left(x_{n}, x\right)\right.\right.\right. \\
& +p(x, F x))\})
\end{aligned}
$$

dengan menggunakan sifat kekontinuan fungsi $\phi$ dan apabila $n \rightarrow \infty$, diperoleh $p(x, F x) \leq$ $\phi(p(x, F x))$.

Hal ini kontradiksi. Oleh karena itu pengandaian salah dan harus diingkar, jadi $p(x, F x)=0$. Akibatnya $F x=x$. Dengan kata lain, $x$ adalah titik tetap $F$. Akan ditunjukkan bahwa titik tetap tersebut tunggal. Andaikan ada titik tetap lain pada $F$, namakan $z$, dengan $z \neq x$. Berdasarkan (8) karena $p(x, x)=0$ maka diperoleh

$$
\begin{aligned}
p(x, z) & =p(F x, F z) \\
& \leq \phi\left(\max \left\{p(x, z), p(x, F x), p(z, F z), \frac{1}{2}(p(x, F z),+p(z, F x))\right\}\right) \\
& =\phi\left(\max \left\{p(x, z), p(x, x), p(z, z), \frac{1}{2}(p(x, z),+p(z, x))\right\}\right) \\
& =\phi(\max \{p(x, z), p(z, z)\}) \\
& =\phi p(x, z)
\end{aligned}
$$

Hal ini kontradiksi. Sehingga pengandaian salah, yang benar adalah titik tetap nya tunggal, yaitu $x=$

Berikut diberikan teorema ketunggalan titik tetap pada pemetaan kontraksi tipe Kannan $\theta-\phi$. Proses pembuktian sejalan dengan teorema ketunggalan titik tetap pada pemetaan kontraksi $\theta-\phi$ diatas. 
Teorema 2.4[5]: Diberikan ruang metrik parsial lengkap $(X, p)$. Jika pemetaan $T: X \rightarrow X$ kontraksi tipe Kannan $\theta-\phi$ maka $T$ mempunyai titik tetap tunggal $x^{*} \in X$ sedemikian hingga barisan $\left\{T^{n}(x)\right\}$ konvergen ke $x^{*} \in X$, untuk setiap $x \in X$.

Bukti: Diberikan $x_{0} \in X$ (Fix/tetap). Didefinisikan barisan $\left\{x_{n}\right\}$, dengan $x_{n}=T x_{n-1}$, untuk setiap $n=$ $1,2,3, \cdots$.

Proses pembuktian $p\left(x_{n}, x_{n}\right) \rightarrow 0$ ketika $n \rightarrow \infty$ sama seperti pembuktian pada Teorema 2.3 diatas. Begitu pula pembuktian barisan $\left\{x_{n}\right\}$ merupakan barisan Cauchy di ruang metrik $\left(X, d_{p}\right)$ analog seperti Teorema 2.3. Karena $\left(X, d_{p}\right)$ adalah ruang metrik lengkap, maka barisan $\left\{x_{n}\right\}$ konvergen, misalkan ke $x^{*} \in X$. Oleh karena itu berlaku $\lim _{n \rightarrow \infty} x_{n}=x^{*}$ dan $p\left(x^{*}, x^{*}\right)=0$. Selanjutnya untuk menunjukkan bahwa $x^{*}$ adalah titik tetap, dapat dibuktikan bahwa $p\left(x^{*}, x^{*}\right)=p\left(T x^{*}, x^{*}\right)=$ $p\left(T x^{*}, T x^{*}\right)=0$. Substitusikan $x=x_{n-1}, y=x^{*}$ ke pertidaksamaan (2), sehingga diperoleh

$$
\begin{gathered}
\theta\left(p\left(T_{x}, T_{y}\right)\right) \leq \phi\left[\theta\left(\frac{p\left(x, T_{x}\right)+p\left(y, T_{y}\right)}{2}\right)\right] \\
\theta\left(p\left(T x_{n-1}, T x^{*}\right)\right) \leq \phi\left[\theta\left(\frac{p\left(x_{n-1}, T x_{n-1}\right)+p\left(x^{*}, T x^{*}\right)}{2}\right)\right] \\
\theta\left(p\left(x_{n}, T x^{*}\right)\right) \leq \phi\left[\theta\left(\frac{p\left(x_{n-1}, x_{n}\right)+p\left(x^{*}, T x^{*}\right)}{2}\right)\right]
\end{gathered}
$$

Apabila $n \rightarrow \infty$ dan berdasarkan Lemma 1.4 serta sifat kekontinuan fungsi $\theta$ dan $\phi$ diperoleh $p\left(x^{*}, T x^{*}\right)=0$. Selanjutnya karena $\theta\left(p\left(T x^{*}, T x^{*}\right)\right) \leq \phi\left[\theta\left(\frac{p\left(x^{*}, T x^{*}\right)+p\left(x^{*}, T x^{*}\right)}{2}\right)\right]$. Maka didapat $p\left(T x^{*}, T x^{*}\right)=0$

Jadi, benar bahwa $x^{*}$ adalah titik tetap pada $T$. Selanjutnya akan dibuktikan ketunggalannya.

Andaikan ada $y^{*}$ titik tetap lainnya pada $T$, sehingga $T x^{*}=x^{*} \neq T y^{*}=y^{*}$, dengan demikian didapatkan $\theta\left(p\left(x^{*}, y^{*}\right)\right)=\left(p\left(T x^{*}, T y^{*}\right)\right) \leq \phi\left(\theta\left(p\left(x^{*}, y^{*}\right)\right)\right)<\theta\left(p\left(x^{*}, y^{*}\right)\right)$. Hal ini kontradiksi. Jadi pengandaian salah, yang benar adalah titik tetap pada $T$ tunggal.

Berikut diberikan contoh agar dapat memberikan ilustrasi dari teorema-teorema yg telah dibahas diatas.

Contoh 2.5: Diberikan himpunan $X=[0, \infty)$ dan didefinisikan $p(x, y)=\max \{x, y\}$. Jelas bahwa $(X, p)$ merupakan ruang metrik parsial lengkap.

Didefinisikan fungsi $\theta:(0, \infty) \rightarrow(1, \infty)$ dengan $\theta(t)=5^{t}$. Didefinisikan pula fungsi $\phi:(1, \infty) \rightarrow$ $(1, \infty)$ dengan

$$
\phi(t)=\left\{\begin{array}{c}
1, \quad 0 \leq t<2 \\
t-1, \quad t \geq 2
\end{array}\right.
$$

Berdasarkan definisi fungsi $\phi$ dan $\theta$ diatas, jelas bahwa $\theta \in \Theta$ dan $\phi \in \Phi$.

Selanjutnya didefinisikan pemetaan $T: X \rightarrow X$ dengan

$$
T x=\left\{\begin{array}{lr}
0, & 0 \leq x<1 \\
\frac{x^{2}}{x+1}, & x \geq 1
\end{array}\right.
$$

Jelas pemetaan $T$ memenuhi semua asumsi pada Teorema 2.2. perhatikan tiga kasus berikut ini: Kasus 1: Jika $x, y \in[0,1)$ dan $x \geq y$ (atau $y \geq x$ ), diperoleh:

$$
\begin{gathered}
p(T x, T y)=0 \\
p(x, y)=x
\end{gathered}
$$




$$
\begin{gathered}
\theta(p(T x, T y))=5^{0}=1 \leq 1=\phi(\theta(p(x, y)))\left(5^{x} \leq 2\right) \\
\theta(p(T x, T y))=5^{0}=1 \leq 5^{x}-1=\phi(\theta(p(x, y)))\left(5^{x}>2\right)
\end{gathered}
$$

Kasus 2: Jika $y \in[0,1)$ dan $x \geq 1$ (atau $x \in[0,1)$ dan $y \geq 1$ ), diperoleh:

$$
\begin{aligned}
& p(T x, T y)=\frac{x^{2}}{x+1} \\
& p(x, y)=x \\
& \theta(p(T x, T y))=5^{\frac{x^{2}}{x+1}} \leq 5^{\frac{x^{2}}{x+1}} \cdot 5^{\frac{1}{2}}-1 \leq 5^{\frac{x^{2}}{x+1}} 5^{\frac{x}{x+1}}=\phi(\theta(p(x, y)))
\end{aligned}
$$

Kasus 3: Jika $x \geq y \geq 1$ atau $(y \geq x \geq 1)$, diperoleh:

$$
\begin{gathered}
p(T x, T y)=\frac{x^{2}}{x+1} \\
p(x, y)=x \\
\theta(p(T x, T y))=5^{\frac{x^{2}}{x+1}} \leq 5^{\frac{x^{2}}{x+1}} \cdot 5^{\frac{1}{2}}-1 \leq 5^{\frac{x^{2}}{x+1}} 5^{\frac{x}{x+1}}=\phi(\theta(p(x, y)))
\end{gathered}
$$

Oleh karena itu berdasarkan kasus 1 sampai kasus 3 diatas, untuk setiap $x, y \in X$ diperoleh

$$
\theta(p(T x, T y)) \leq \phi(\theta(p(x, y)))
$$

Fungsi $T$ pada contohnya ini mempunyai titik tetap tunggal, yaitu $x=0$ adalah titik tetapnya. Pada contoh ini, kondisi seperti Teorema 2.2 tidak dipenuhi apabila metrik parsial $p$ menjadi metrik biasa (usua) $d$. Berikut contoh penyangkalananya.

Misalkan $x=2$, dan $y=2.5$ maka diperoleh $d(T x, T y)=\frac{19}{42}$ dan $d(x, y)=0.5$

$$
\theta(d(T x, T y))=5^{\frac{19}{42}} \geq 5^{0.5}-1=\phi(\theta(p(x, y)))
$$

Hal ini tidak memenuhi kondisi diatas.

\section{Kesimpulan}

Teorema ketunggalan titik tetap yang dikemukakan oleh Tao dkk sejalan dengan yang dikemukakan oleh Ishak dkk, perbedaannya adalah bahwa pada Ishak dkk tidak mendefinisikan pemetaan kontraksi $\theta-\phi$. Akan tetapi syarat perlunya diberikan dengan suatu hubungan pertidaksamaan pada metriknya. Selain itu, Proses pembuktian teorema ketunggalan titik tetap pada pemetaan kontraksi tipe Kannan $\theta-\phi$ sejalan dengan teorema ketunggalan titik tetap pada pemetaan kontraksi $\theta-\phi$.

\section{Referensi}

[1] Dingwei Zheng, Zhangyong Cai, Pei Wang. 2017. New _xed point theorems for $\theta-\phi$ contraction in complete metrik spaces, Journal of Nonlinear Sciences and Applications, 10 (2017), 2662-2670.

[2] Ishak A, Ferhan S, Hakan S, 2010, Generalized contractions on partial metrik spaces, Elsevier: Topology and its Applications, 2010, 2778-2785.

[3] S. G. Matthews, 1992. Partial Metrik Topology, Research Report 212, Dept. of Computer Science, University of Warwick.

[4] S. G. Matthews. 1994. Partial metrik topology, General Topology and its Applications, Annals of the New York Academy of Sciences, 728 (1994), 183-197.

[5] Tao Hu, Dingwei Z, Jingren Z. 2018. Some new Fixed Point Theorems on partial metrik spaces. IJMA, Vol 12, 2018 no 7 . 